\title{
Overexpression of MicroRNA-1 in Prostate Cancer Cells Modulates the Blood Vessel System of an In Vivo Hen's Egg Test-Chorioallantoic Membrane Model
}

\author{
ARIK REUTER ${ }^{1}$, AXEL SCKELL ${ }^{2}$, LARS-OVE BRANDENBURG ${ }^{3}$, \\ MARTIN BURCHARDT ${ }^{1}$, AXEL KRAMER $^{4}$ and MATTHIAS B. STOPE ${ }^{1}$ \\ ${ }^{1}$ Department of Urology, University Medicine Greifswald, Greifswald, Germany; \\ ${ }^{2}$ Department of Trauma, Hand and Reconstructive Surgery, Rostock University Medical Center, Rostock, Germany; \\ ${ }^{3}$ Department of Anatomy and Cell Biology, RWTH Aachen University, Aachen, Germany; \\ ${ }^{4}$ Institute of Hygiene and Environmental Medicine, University Medicine Greifswald, Greifswald, Germany
}

\begin{abstract}
Background/Aim: In prostate cancer $(P C)$, the formation of new blood vessels is stimulated by hypoxic conditions, androgens, and a number of molecular factors including microRNAs. MicroRNA-1 (miR-1) has been characterized in some tumor entities as anti-angiogenic, but this has not yet been investigated in PC. Materials and Methods: PC cells stably overexpressing miR-1 (LNCaPmiR-1) were incubated on an in vivo hen's egg testchorioallantoic membrane (HET-CAM) model and compared to maternal LNCaP cells. Cell growth, blood vessel organisation, and total blood vessel area were analysed. Results: Both matrigel-embedded LNCAP and LNCAP-miR-I cells formed compact tumor-like cell aggregates on the CAM of the HET-CAM model. Although not quantifiable, bleeding of the CAM and remodelling of the blood vessel network in the CAM indicated an influence of $m i R-1$ on the vascular system. The statistically significant decrease in the total surface area of blood vessels in the visible CAM section to $79.4 \%$ of control cells demonstrated the antiangiogenic properties of miR-1 for the first time. Conclusion: MiR-1 had a tumor-suppressive and anti-angiogenic effect in an in vivo PC model. In the clinic, miR-1-mediated anti-angiogenesis would result in reduced tumor supply and increased hypoxic stress inside the tumor. Thus, miR-1 restoration by nucleic
\end{abstract}

This article is freely accessible online.

Correspondence to: Matthias Stope, Department of Urology, University Medicine Greifswald, Ferdinand-Sauerbruch-Straße, 17475 Greifswald, Germany. Tel: +49 38348680436, Fax: +49 38348680435, e-mail: matthias.stope@uni-greifswald.de

Key Words: MicroRNA-1, prostate cancer, hen's egg testchorioallantoic membrane model, angiogenesis. acid-based miR-1 mimetics would represent a promising option for future PC therapy.

Angiogenesis represents one of the hallmarks of cancer and thus is an important prerequisite for the formation of complex solid tumors (1). The diffusion limit for oxygen is 100-200 $\mu \mathrm{m}$. For multicellular organsims, growth beyond that critical size at which cells can be adequately supplied by diffusion is not possible. Therefore, mammalian cells depend on oxygen being transported through the blood vessel system.

Development and reconstruction of blood vessels are regulated by a finely balanced system of pro- and antiangiogenetic molecules. Among these, vascular endothelial growth factor (VEGF) and angiopoietin (Ang) family members play a predominant role (2). During tumor development, new tumor-associated blood vessels are formed by sprouting or intussusception of existing blood vessels. This involves a temporally and spatially coordinated expression of angiogenetic factors and their inhibitors. The regulation differs significantly from physiological angiogenesis during development, but the underlying molecular mechanims are poorly understood (3). Due to the irregular organization of the tumor-associated blood vessel network, some areas of the tumor are more than 100-200 $\mu \mathrm{m}$ distant from a blood vessel. The resulting lower oxygen concentration therefore leads to a permanent hypoxic environment in at least parts of the tumor (4).

In prostate cancer (PC), the formation of new blood vessels is stimulated by hypoxic conditions and androgens, with VEGF playing a major role in angiogenic signalling (5). A number of other molecular factors, including some microRNAs, have also been described to play an importnat role in angiogenesis. MicroRNA-1 (miR-1) has been characterized in many tumor entities as a tumor suppressor [reviewed in (6)]. Initial studies indicated that miR-1 also 
has anti-angiogenic properties (7-10), but this has not yet been investigated for PC. The aim of this study was to explore the anti-angiogenic effects of the overexpression of miR-1 in PC cells in an in vivo hen's egg test-chorioallantoic membrane (HET-CAM) model.

\section{Materials and Methods}

Cell culture. Prostate cancer (PC) cells LNCaP (Cell Lines Service; CLS, Eppelheim, Germany) and LNCaP cells stably overexpressing miR-1 [LNCaP-miR-1; (11)] were grown in RPMI 1640 media with $10 \%$ fetal bovine serum and $1 \%$ penicillin/streptomycin (PAN Biotech, Aidenbach, Germany) in a $5 \% \mathrm{CO}_{2}$ atmosphere and $37^{\circ} \mathrm{C}$.

In vitro cell growth assay. Cell growth was examined by using a CASY Cell Counter and Analyzer Model TT (Roche Applied Science, Mannheim, Germany). Adherent cells were detached by treatment with trypsin and suspended in CASYton (Roche Applied Science) in a 1:100 dilution. Measurement of $400 \mu \mathrm{l}$ cell suspension was performed in 3 cycles using a capillary of $150 \mu \mathrm{m}$ in diameter. Discrimination between living cells, dead cells and cellular debris was performed using gate settings of $15.45 \mu \mathrm{m}$ (living cells $v s$. dead cells) and $7.20 \mu \mathrm{m}$ (dead cells $v s$. cell debris).

RNA preparation and cDNA synthesis. For detection of miR-1 molecules, total RNA was prepared using peqGOLD Trifast Reagent (Peqlab Biotechnology, Erlangen, Germany) according to the manufacturer's instructions. RNA concentration was determined utilizing a Nanodrop 2000c UV/vis spectrophotometer (Peqlab Biotechnology) and RNA was stored at $-80^{\circ} \mathrm{C}$. For reverse transcription $100 \mathrm{ng}$ of total RNA were applied to the Superscript II Reverse Transcriptase (Life Technologies, Darmstadt, Germany) according to the protocol of Chen et al. (12). Stem-loop primers for reverse transcription were designed as follows: miR-1 stem-loop: 5'GTCGTATCCAGTGCAGGGTCCGAGGTATTCGCACTGGATAC GACATACAT-3'; U6 stem-loop: 5'-GTCATCCTTGCGCAGG-3'.

Quantitative real-time polymerase chain reaction. Quantification of miR-1 was performed with the SensiMix SYBR hi-ROX Kit (Bioline, Luckenwalde, Germany) on a CFX96 Real-Time System (Bio-Rad, München, Germany) with the CFX Manager software (Bio-Rad). The sequences of the PCR primers were as follows: miR-1 forward: 5'-GCCCGCTGGAATGTAAAGAAGTATG-3'; miR-1 reverse: 5'-GTGCAGGGTCCGAGGT-3'; U6 forward: 5'-CGCTTCGGC AGCACATATAC-3'; U6 reverse: 5'-AGGGGCCATGCTAATCTTCT3 '. For quantification, miR-1 signals were standardized to U6 RNA as reference.

Hen's egg test-chorioallantoic membrane model. Fertilized, specific pathogen-free Leghorn chicken eggs were purchased from Lohmann Tierzucht (Cuxhaven, Germany). Eggs were incubated at $37^{\circ} \mathrm{C}$ with a relative humidity of $62 \%$ in a Thermal de Lux 200 (J. Hemel Brutgeräte, Verl, Germany). For the first 6 days, the eggs were automatically rotated with 1 rotation/12 h. Starting from day 7 the eggs were placed with the blunt end, containing the air cell, facing downwards into the breeder and incubated for 7 additional days without further rotation. On day 8 eggs were screened with a Powerlux Egg Tester Lamp (J. Hemel Brutgeräte) and unfertilized eggs were eliminated. Before preparation, the contour of the air chamber was marked and the egg shell was carefully removed. For subsequent incubation the egg opening was covered with a sterile Tegaderm mesh (3M, Neuss, Germany). For incubation experiments $5 \times 10^{6}$ cells were mixed with $30 \mu 1$ Matrigel (Corning, Wiesbaden, Germany), inoculated to the CAM and incubated for $144 \mathrm{~h}$. During the incubation period the tumor-like cell aggregates were photomicroscopically archived.

Determination of the tumor-like cell aggregate volume. Volume determination was carried out using frozen tumor-like cell aggregates that were assumed to be spherical segments. Height $h$ and radius a of an aggregate was measured and the volume $\mathrm{V}$ was calculated using the formula $\mathrm{V}=\mathrm{h} \pi / 6\left(3 \mathrm{a}^{2}+\mathrm{h}^{2}\right)$ as depicted in Figure $1 \mathrm{G}$ and $\mathrm{H}$.

Determination of the total area of all blood vessels. To determine the total area of blood vessels on the prepared CAM section, the vessels were drawn according to their thickness with the open source graphic evaluation program Image $J$ (https://imagej.nih.gov/ij). Afterwards, the total area of the lines was calculated by the program.

Statistics. Statistical comparisons of at least five independent measurements were performed using the unpaired Student's $t$-test with $95 \%$ confidence interval. For all statistical analyses results of $p \leq 0.05\left(^{*}\right)$ and $p \leq 0.01\left(^{* *}\right)$ were considered significant with data given as mean $\pm \mathrm{SD}$.

\section{Results}

To investigate the angiogenic properties of miR-1, the cell line LNCaP-miR-1 was used in an in vivo HET-CAM model. LNCaP-miR-1 is a recombinant cell line stably overexpressing the tumor suppressor miR-1 (129.6-fold \pm 69 .4-fold, $p=0.0424$; Figure 2A) and, in cell culture growth experiments, displays the expected inhibition of cell growth during the incubation (Figure 2B). Due to the stable overexpression of the microRNA, the growth inhibitory effect remained verifiable over the entire incubation period of $240 \mathrm{~h}$.

Both the matrigel-embedded LNCaP control cells (Figure $1 \mathrm{~A}, \mathrm{C}, \mathrm{E})$ and the miR-1 overexpressing LNCaP-miR-1 cells (Figure 1B, D, F) formed compact tumor-like cell aggregates on the CAM of the HET-CAM model. These aggregates were maintained in culture up to $144 \mathrm{~h}$. To determine the tumor-like cell aggregate volume, aggregates were deep-frozen and the height $h$ and the radius a of the aggregate assumed as a spherical segment were measured. The volume $\mathrm{V}$ was then calculated using the formula $\mathrm{V}=\mathrm{h} \pi / 6\left(3 \mathrm{a}^{2}+\mathrm{h}^{2}\right)$ (Figure $\left.1 \mathrm{G}, \mathrm{H}\right)$. Although compacting of the cell aggregates was observed (Figure 1A-F), analysis of the calculated volume revealed no significant difference between the two cell lines (LNCaP: $43.6 \pm 10.4 \mathrm{~mm}^{3}$; LNCaP-miR-1: $46.5 \pm 8.2 \mathrm{~mm}^{3} ; p=0.4401$; Table I).

Even the microscopic examination of the tumor-like cell aggregates showed that the overexpression of miR-1 led to changes in the vascular structure in the CAM. During the first days of incubation, the vascular system resembled a 

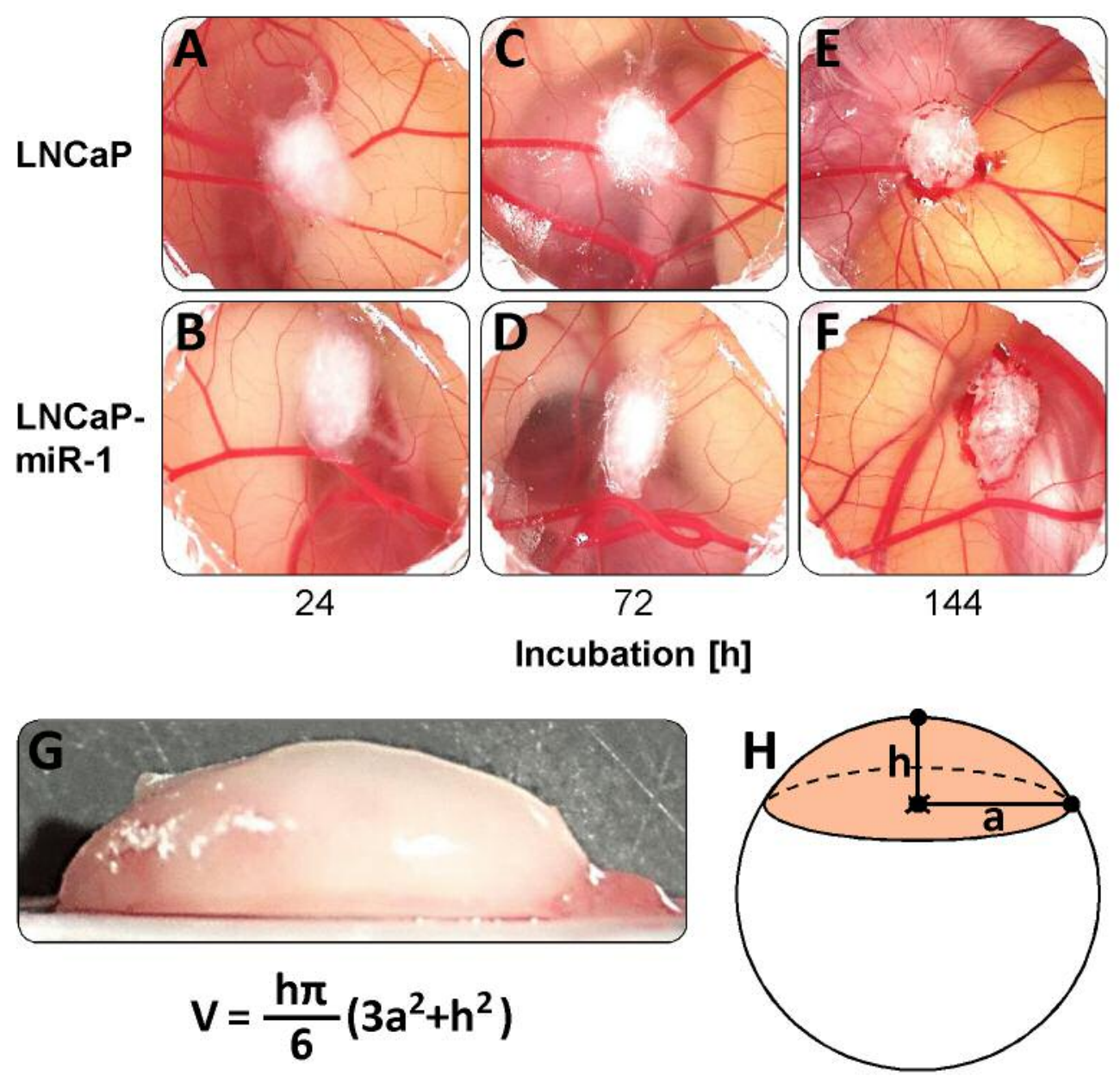

Figure 1. Formation of tumor-like cell aggregates of LNCaP $(A, C, E)$ and LNCaP-miR-1 $(B, D, F)$ cells in the in vivo HET-CAM model. (G, H) Calculation of the tumor-like cell aggregate volume assuming a spherical segment geometry.

Table I. Statistical analysis of the calculated tumor-like cell aggregate volume and the total area of blood vessels.

\begin{tabular}{llll}
\hline & $\mathrm{n}$ & $\mathrm{MW}$ & $p$-Value \\
\hline Volume of tumor-like cell aggregates $\left[\mathrm{mm}^{3}\right]$ & & & \\
$\quad$ LNCaP & 13 & $43.6 \pm 10.4$ & 0.4401 \\
LNCaP-miR-1 & 13 & $46.5 \pm 8.2$ & \\
Total area of blood vessels $\left[\mathrm{mm}^{2}\right]$ & & & \\
$\quad$ LNCaP & 18 & $1.07 \pm 0.32$ & 0.0144 \\
LNCaP-miR-1 & 18 & $0.85 \pm 0.17$ & \\
\hline
\end{tabular}

uniform network (Figure 3A, B). After $144 \mathrm{~h}$, however, the basic structure had changed and most of the blood vessels now ran radially towards the tumor-like cell aggregate (Figure 3C, D). For further evaluation of the blood vessel remodelling, the total area covered by all blood vessels in the visual field was determined after $144 \mathrm{~h}$ (Figure 3E, F). This analysis showed that overexpression of miR-1 significantly reduced the total area of blood vessels from $1.07 \pm 0.32 \mathrm{~mm}^{2}$ in the CAM section of eggs incubated with LNCaP cells to $0.85 \pm 0.17 \mathrm{~mm}^{2}$ in the CAM section of eggs incubated with LNCaP-miR-1 cells ( $p=0.0144$; Table I).

\section{Discussion}

In $\mathrm{PC}$, the expression of miR-1 is down-regulated compared to healthy tissue and continues to decrease during tumor progression (13-17). At the cellular level, miR-1 possesses anti-oncogenic properties, inhibits proliferation and metastasis, and induces apoptosis $(11,18-21)$. A main target in PC cells is the proliferative androgen receptor $(22,23)$. Although shown during tissue development and remodelling, including malignant degeneration (7-10), there are still no data available on the angiogenic properties of miR-1 in PC cells. 

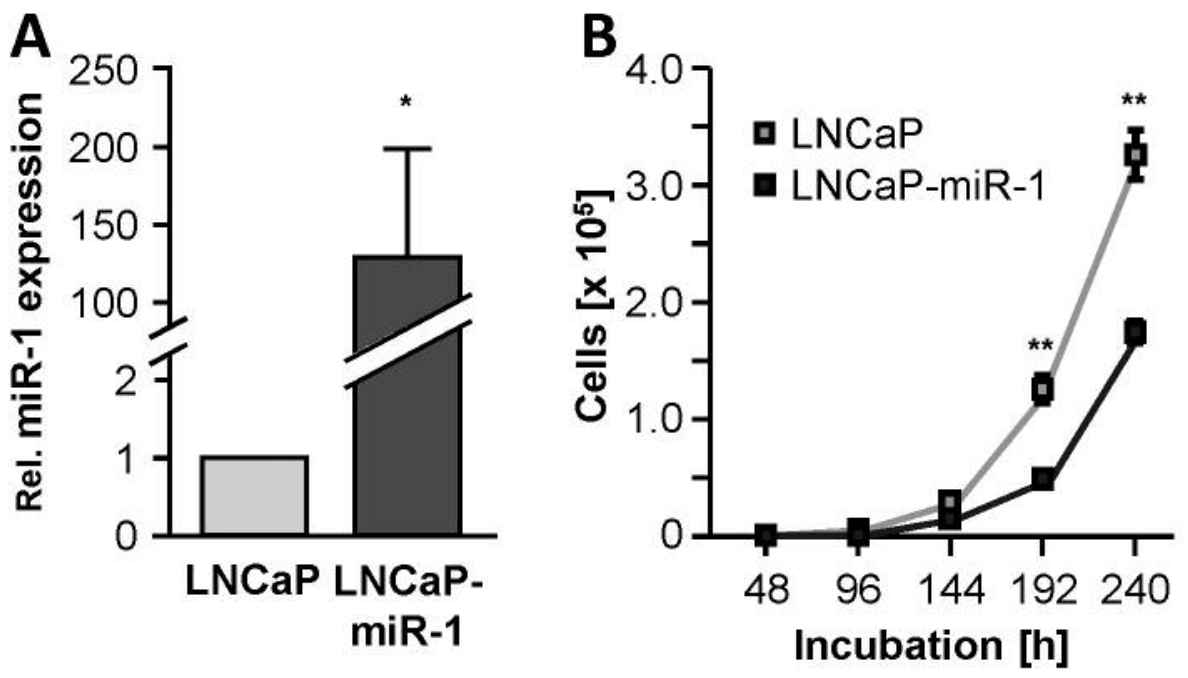

Figure 2. Characterization of the miR-1 overexpressing cell line LNCaP-miR-1. (A) Elevated levels of miR-1 in LNCaP-miR-1 cells compared to maternal LNCaP cells. (B) Tumor-suppressive and anti-proliferative properties of miR-1 overexpressing LNCaP-miR-1 cells compared to maternal LNCaP cells.

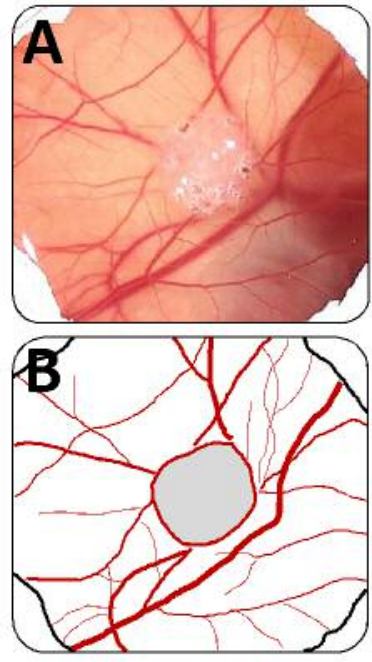

72
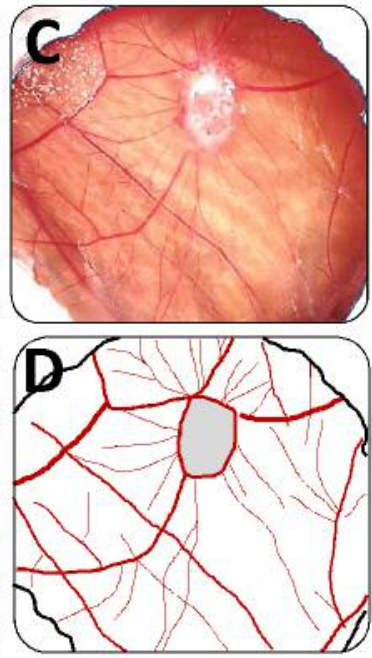

144
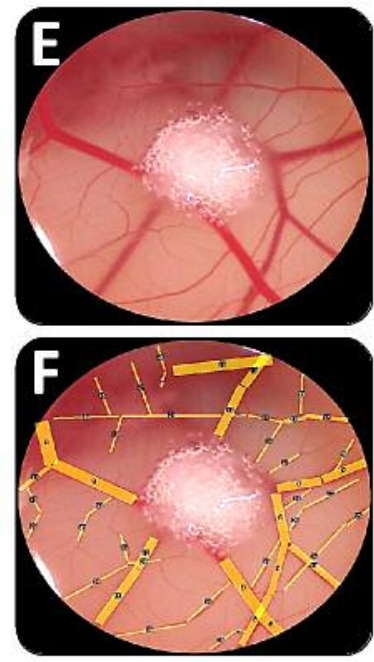

\section{Incubation [h]}

Figure 3. Organization of the blood vessel system after $72 h(A, B)$ and $144 h(C, D)$ of incubation. (E, F) Calculation of the total area of blood vessels utilizing the open source graphic evaluation program Image $J$.

Using the HET-CAM in vivo model, the effects of miR-1 overexpression on the growth of PC tumor cells and on the architecture of the blood vessel system in the CAM were investigated. The HET-CAM was introduced as a sensitive screening model to analyse the irritative potential and acute inflammation (24) and replace the Draize irritation test on rabbit (25). Additionally, in the last years the HET-CAM was used as a model to investigate inflammation, angiogenesis, apoptosis and mutagenicity (25-27). An ethical advantage of the HET-CAM is that it is not classified as an animal experiment until the 11th day of incubation, because no nerve tissue has developed and thus no pain perception occurs until then (28). Thus, this model is suitable to analyse the anti-angiogenic effect of miR-1. 
Due to the three-dimensional growth, the exact determination of tumor proliferation in the HET-CAM model proved to be difficult. Single cell counting failed because PC cells could not be separated from the compact tumor-like cell aggregates. Furthermore, analysis of two-dimensional microscopic images or the total weight of the aggregates (29, 30) also seemed inappropriate and too inaccurate to determine tumor growth. Therefore, and in order to more accurately calculate the three-dimensional cell growth, the volume was finally calculated after determining the height and radius of the aggregates.

Although a clear antiproliferative effect of miR-1 could be shown in cell culture experiments, this could not be confirmed in the in vivo HET-CAM model. However, there was a clear compression of the PC cells during incubation. This suggests that cell proliferation did take place, but that it may not have had a pronounced effect on the volume of the tumor-like cell aggregates. In addition, the arithmetical determination of the aggregate volume may be too inaccurate to determine small differences in growth.

In addition to the control of cell growth, miR-1 is also thought to be a pivotal factor for the regulation of tumorassociated blood vessels. With regard to the HET-CAM model, bleeding into the CAM has been described as a first common symptom of blood vessel sprouting and vascular system modulation (31). In our experiments, bleeding was identified in about half of all eggs. This was slightly but not significantly declined in eggs inoculated with LNCaPmiR-1 (data not shown). More obvious was restructuring of the vessel system around the tumor-like cell aggregates In tumor progression, this plays an essential role in the complex setting of overcoming host vessel regression and the induction of neo-angiogenesis $(2,32)$. Within a few days, the previously rather regular network structure of the blood vessels was mostly restructured and exhibited a radial orientation towards the tumor cells. This effect appeared to be more prominent in LNCaP-miR-1 cells, but could not be quantified and therefore not statistically analysed. The analysis of the entire vessel surface as a measure of the quantity and capacity of the vascular system finally demonstrated the anti-angiogenetic properties of miR-1 in PC cells. The tumor-associated vascular system was significantly reduced in PC cells overexpressing miR-1.

The data presented in this study verified the tumor suppressive potential of miR-1 and demonstrated the antiangiogenic effect of miR-1, for the first time, in an in vivo PC model. In the clinic, miR-1-mediated anti-angiogenesis would result in reduced blood supply to the tumor and increased hypoxic stress inside the tumor, which in sum would lead to tumor regression. Thus, miR-1 restoration by applying nucleic acid-based miR-1 mimetics would represent a promising option for future PC therapy.

\section{Conflicts of Interest}

The Authors declare that they have no competing interests.

\section{Acknowledgements}

Part of this work was supported by a grant to A.R. from the Gerhard Domagk Grant of the University Medicine Greifswald.

\section{References}

1 Hanahan D and Weinberg RA: Hallmarks of cancer: the next generation. Cell 144: 646-674, 2011.

2 Yancopoulos GD, Davis S, Gale NW, Rudge JS, Wiegand SJ and Holash J: Vascular-specific growth factors and blood vessel formation. Nature 407: 242-248, 2000.

3 Carmeliet P and Jain RK: Angiogenesis in cancer and other diseases. Nature 407: 249-257, 2000.

4 Helmlinger G, Yuan F, Dellian M and Jain RK: Interstitial pH and $\mathrm{pO} 2$ gradients in solid tumors in vivo: high-resolution measurements reveal a lack of correlation. Nat Med 3: 177-182, 1997.

5 Eisermann $\mathrm{K}$ and Fraizer G: The androgen receptor and VEGF: mechanisms of androgen-regulated angiogenesis in prostate cancer. Cancers 9: E32, 2017.

6 Weiss $\mathrm{M}$, Brandenburg LO, Burchardt $\mathrm{M}$ and Stope MB: MicroRNA-1 properties in cancer regulatory networks and tumor biology. Crit Rev Oncol Hematol 104: 71-77, 2016.

7 Lu J, Zhao FP, Peng Z, Zhang MW, Lin SX, Liang BJ, Zhang B, Liu X, Wang L, Li G, Tian WD, Peng Y, He ML and Li XP: EZH2 promotes angiogenesis through inhibition of miR1/Endothelin-1 axis in nasopharyngeal carcinoma. Oncotarget 5: 11319-11332, 2014.

8 Lin CY, Lee HC, Fu CY, Ding YY, Chen JS, Lee MH, Huang WJ and Tsai HJ: miR-1 and miR-206 target different genes to have opposing roles during angiogenesis in zebrafish embryos. Nat Commun 4: 2829, 2013.

9 Stahlhut C, Suarez Y, Lu J, Mishima Y and Giraldez AJ: miR-1 and miR-206 regulate angiogenesis by modulating VegfA expression in zebrafish. Development 139: 4356-4364, 2012.

10 Xie M, Dart DA, Guo T, Xing XF, Cheng XJ, Du H, Jiang WG, Wen $\mathrm{XZ}$ and Ji JF: microRNA-1 acts as a tumor suppressor microRNA by inhibiting angiogenesis-related growth factors in human gastric cancer. Gastric Cancer 21: 41-54, 2018.

11 Stope MB, Stender C, Schubert T, Peters S, Weiss M, Ziegler P, Zimmermann U, Walther $\mathrm{R}$ and Burchardt $\mathrm{M}$ : Heat-shock protein HSPB1 attenuates microRNA miR-1 expression thereby restoring oncogenic pathways in prostate cancer cells. Anticancer Res 34: 3475-3480, 2014.

12 Chen C, Ridzon DA, Broomer AJ, Zhou Z, Lee DH, Nguyen JT, Barbisin M, Xu NL, Mahuvakar VR, Andersen MR, Lao KQ, Livak KJ and Guegler KJ: Real-time quantification of microRNAs by stem-loop RT-PCR. Nucleic Acids Res 33: e179, 2005.

13 Kojima S, Chiyomaru T, Kawakami K, Yoshino H, Enokida H, Nohata N, Fuse M, Ichikawa T, Naya M, Nakagawa M and Seki $\mathrm{N}$ : Tumour suppressors miR-1 and miR-133a target the oncogenic function of purine nucleoside phosphorylase (PNP) in prostate cancer. Br J Cancer 106: 405-413, 2012. 
14 Karatas OF, Guzel E, Suer I, Ekici ID, Caskurlu T, Creighton CJ, Ittmann $M$ and Ozen $M$ : miR-1 and miR-133b are differentially expressed in patients with recurrent prostate cancer. PLoS ONE 9: e98675, 2014.

15 Hudson RS, Yi M, Esposito D, Watkins SK, Hurwitz AA, Yfantis HG, Lee DH, Borin JF, Naslund MJ, Alexander RB, Dorsey TH, Stephens RM, Croce CM and Ambs S: MicroRNA1 is a candidate tumor suppressor and prognostic marker in human prostate cancer. Nucleic Acids Res 40: 3689-3703, 2012.

16 Ambs S, Prueitt RL, Yi M, Hudson RS, Howe TM, Petrocca F, Wallace TA, Liu CG, Volinia S, Calin GA, Yfantis HG, Stephens $\mathrm{RM}$ and Croce CM: Genomic profiling of microRNA and messenger RNA reveals deregulated microRNA expression in prostate cancer. Cancer Res 68: 6162-6170, 2008.

17 Wei W, Leng J, Shao H and Wang W: miR-1, a potential predictive biomarker for recurrence in prostate cancer after radical prostatectomy. Am J Med Sci 353: 315-319, 2017.

18 Chang J, Xu W, Du X and Hou J: MALAT1 silencing suppresses prostate cancer progression by upregulating miR-1 and downregulating KRAS. Onco Targets Ther 11: 3461-3473, 2018.

19 Chung, Tony KH, Cheung TH, Huen NY, Wong, Katherine WY, Lo, Keith WK, Yim SF, Siu, Nelson SS, Wong YM, Tsang PT, Pang MW, Yu MY, To KF, Mok SC, Wang VW, Li C, Cheung, Albert Y K, Doran G, Birrer MJ, Smith DI and Wong YF: Dysregulated microRNAs and their predicted targets associated with endometrioid endometrial adenocarcinoma in Hong Kong women. Int J Cancer 124: 1358-1365, 2009.

20 Chang YS, Chen WY, Yin JJ, Sheppard-Tillman H, Huang J and Liu YN: EGF receptor promotes prostate cancer bone metastasis by downregulating miR-1 and activating TWIST1. Cancer Res 75: 3077-3086, 2015.

21 Liu YN, Yin J, Barrett B, Sheppard-Tillman H, Li D, Casey OM, Fang L, Hynes PG, Ameri AH and Kelly K: Loss of androgenregulated microRNA 1 activates SRC and promotes prostate cancer bone metastasis. Mol Cell Biol 35: 1940-1951, 2015.

22 Stope MB, Peters S, Grossebrummel H, Zimmermann U, Walther R and Burchardt M: Androgen receptor (AR) inhibitor ErbB3-binding protein-1 (Ebp1) is not targeted by the newly identified AR controlling signaling axis heat-shock protein HSP27 and microRNA miR-1 in prostate cancer cells. World J Urol 33: 323-327, 2014

23 Stope MB, Bradl J, Peters S, Streitborger A, Weiss M, Zimmermann U, Walther R, Lillig CH and Burchardt M: Shortened isoforms of the androgen receptor are regulated by the cytoprotective heat-shock protein HSPB1 and the tumorsuppressive microRNA miR-1 in prostate cancer cells. Anticancer Res 33: 4921-4926, 2013.
24 Marquardt C, Matuschek E, Bolke E, Gerber PA, Peiper M, Seydlitz-Kurzbach J, Buhren BA, van Griensven M, Budach W, Hassan M, Kukova G, Mota R, Höfer D, Orth K and Fleischmann W: Evaluation of the tissue toxicity of antiseptics by the hen's egg test on the chorioallantoic membrane (HETCAM). Eur J Med Res 15: 204-209, 2010.

25 Bender C, Partecke LI, Kindel E, Doring F, Lademann J, Heidecke CD, Kramer A and Hübner NO: The modified HETCAM as a model for the assessment of the inflammatory response to tissue tolerable plasma. Toxicol In Vitro 25: 530537, 2011.

26 Partecke LI, Evert K, Haugk J, Doering F, Normann L, Diedrich S, Weiss FU, Evert M, Huebner NO, Guenther C, Heidecke CD, Kramer A, Bussiahn R, Weltmann KD, Pati O, Bender C and von Bernstorff W: Tissue tolerable plasma (TTP) induces apoptosis in pancreatic cancer cells in vitro and in vivo. BMC Cancer 12: 473, 2012.

27 Kluge S, Bekeschus S, Bender C, Benkhai H, Sckell A, Below $\mathrm{H}$, Stope $\mathrm{MB}$ and Kramer A: Investigating the mutagenicity of a cold argon-plasma jet in a HET-MN model. PLoS One 11: e0160667, 2016.

28 Liebsch $\mathrm{M}$ and Spielmann H: Currently available in vitro methods used in the regulatory toxicology. Toxicol Lett 127: 127-134, 2002.

29 Busch M, Grosse-Kreul J, Wirtz JJ, Beier M, Stephan H, RoyerPokora B, Metz K and Dunker N: Reduction of the tumorigenic potential of human retinoblastoma cell lines by TFF1 overexpression involves p53/caspase signaling and miR-18a regulation. Int J Cancer 141: 549-560, 2017.

30 Skowron MA, Sathe A, Romano A, Hoffmann MJ, Schulz WA, van Koeveringe GA, Albers P, Nawroth R and Niegisch G: Applying the chicken embryo chorioallantoic membrane assay to study treatment approaches in urothelial carcinoma. Urol Oncol 35: 544.e11-544.e23, 2017.

31 Feflea S, Cimpean AM, Ceausu RA, Gaje P and Raica M: Effects of antibodies to EG-VEGF on angiogenesis in the chick embryo chorioallantoic membrane. In Vivo 26: 793-797, 2012.

32 Hanahan D and Folkman J: Patterns and emerging mechanisms of the angiogenic switch during tumorigenesis. Cell 86: 353-364, 1996. 